\title{
Design and Development Strategies of Wisdom Tourism Framework of Shandong Province Based on Individual Perspective
}

\author{
Guang Yang ${ }^{1, a}$, Jing Yang ${ }^{2, b}$, Yongqing Yang ${ }^{1,3, \mathrm{c}^{,} \text {, }}$ \\ Tingting $\mathrm{He}^{1, \mathrm{~d}}$ and Dan $\mathrm{Li}^{4, \mathrm{e}}$ \\ ${ }^{1}$ Shandong Business and Technology University, Yantai Shandong, China 264005 \\ ${ }^{2}$ Ludong University, Yantai Shandong, China 264025 \\ ${ }^{3}$ Shandong Engineering Technology Center of Internet of Vehicles \\ ${ }^{4}$ Yantai Industry and Trade Technicians College, Yantai Shandong, China 264005 \\ asdytyg@126.com, b463470864@qq.com, ${ }^{\mathrm{c}} 42943289 @ q q . c o m,{ }^{\mathrm{d}}$ evita0508@163.com, \\ "459087357@qq.com
}

Keywords: Wisdom tourism; Design; Development strategies; Individual perspective

\begin{abstract}
With the development of tourism in the field of information technology, wisdom tourism will come into being which relies on the portable Internet devices and bases on mobile, cloud computing, the Internet and other new technologies as the platform. Meanwhile, visitors experience as the core content of tourist more and more emphasized by tourism enterprises. And the wisdom tourism not only has a pivotal role in enhancing the visitor experience levels, but also promotes tourism transformation and upgrading. This paper takes Shandong for example to do some research on the wisdom tourism development in Shandong Province, and analyzes the wisdom tourism prospects and tourist's overall perception on Shandong wisdom tourism. Meanwhile, this paper constructs level- system of wisdom tourism and designs the framework of Shandong Province wisdom Tourism, and proposes countermeasures on wisdom future tourism development which refer to provincial tourism resource and provincial travel information resources and tourism information platform integration platform.
\end{abstract}

\section{Introduction}

Wisdom tourism is a new way to meet the individual needs of tourists, enhance the travel experience, and get the new high-quality tourism services, which relies on the traditional tourist attractions, tourism enterprises and uses the portable terminal access equipment, cloud computing, networking and other new technologies to perceive information of tourism resources, tourism economy, tourism, and tourists so that tourists can keep abreast of such information in a timely manner and arrange travel plans and adjustments to achieve all kinds of tourist information. Wisdom tourism, in some sense, combines the traditional tourism resources, social resources, information systems and tourism platform to achieve maximum optimization of resources, which is a systematic and intensive revolution of the traditional tourism. Zhang Lingyun considers the four core competencies of wisdom tourism are networking, mobile communications, cloud computing artificial intelligence, and so on [1]. Liujun Lin, Fan Yunfeng raise the wisdom of tourism has a certain role in helping to solve the problem space tourist information asymmetry .And based on intelligence provided by the smart tourism services, tourists can smoothly resolve language barriers, and other aspects of comprehensive information in order to improve decision-making tourist travel [2]. Meng Li suggests that certain correlation exists between tourism information and intelligence by analyzing the wisdom of travel and tourism information connotation of the concept, which means the former is the basis for the successful development of the latter, while the latter is a continuation of the former [3].

Currently, some provinces and cities gradually promote the wisdom tourism in our country and advanced travel experience also demonstrates the wisdom of wisdom excellent results in the integration of tourism resources and symmetric services and other aspects of faith. Min Yan 
analyzes the present situation and characteristics of the construction of wisdom tourism Nanjing, Jiangsu, and Nanjing to make certain comments and recommendations on the future of tourism in the wisdom of building programs [4]. Song Dongning for the tourism situation in Harbin, proposes to accelerate cooperation between tourism enterprises and other enterprises in the government-led premise to achieve wisdom Harbin travel process as soon as possible [5]. Shen Ping and Shu Weiying consider the wisdom of tourism should be dealt with wisdom tourism management, tourism marketing, tourism and services [6]. Yao Guozhang finds South Korea's "i Tour Seoul" handheld mobile tourist information service platform not only can effectively achieve the scenic tourist location, quick access to tours of scenic spots, perfect tourists reservations and ticketing systems, but also provide in-depth tour line extension and extension smart phone leasing business for tourists [7].

\section{The Necessity and Significance of the Wisdom of Tourism Development in Shandong Province}

Shandong Province is rich in tourism resources, which mountains and rivers of geographical features and rich cultural and historical heritage of the tourists have a great appeal to tourists. With the improvement of living standards, the proportion of tertiary industry in GDP increased gradually. According to the statistics, tourism growth and tourism revenues of Shandong province have shown an obvious rising trend. 2014 total tourism revenue exceeded, w600 billion yuan with an increase of $14.5 \%$, comparing with the previous year [8]. In 2015, the total tourism consumption reached 706.25 billion yuan, equivalent to $9.9 \%$ of the province's GDP, which had an increase of $14.0 \%$ [8]. It is worth mentioning that, in the face of such a blowout of tourism growth, simply relying on the traditional tourism management model cannot effectively solve the various problems spurt of growth in tourism. Problems are still particularly prominent, such as tourism development in the province. In addition, there is a more or less fragmentation of public information in the process of integration of tourism resources, such as travel, tourism, public information is not comprehensive, tourism public information updates slowly, and tourism content is not rich, tourism public information is not accurate and reliable, tourism public information is inadequate, and allocation of travel resources is unreasonable. Therefore, using the price instruments, such as raising ticket prices and seasonal adjustment to split tickets visitors, or advertising spots to enhance the tourism image, are often difficult to solve scenic fundamentally irrational allocation of resources, low tourist satisfaction and other issues.

Shandong Provincial Tourism Bureau in the "2014 China City Tourism Development Strategy Seminar" made a clear direction of tourism development in Shandong which is the "wisdom of tourism", Shandong has already begun the process of tourism development of wisdom, such as Tai' an City travel network construction to achieve a variety of functions tourism hub which can quickly dispatch tour bus, timely view the local tour guides and tour information. Meanwhile "Tai' an tourism" and "World of Tai' an" Two micro-channel platform are formally launched in 2014, and the micro-channel platform integrates Tai' an public information resources into tourism consumption, tourism promotion platform news and information via the Raiders, referrals and services in three sections, so that visitors can experience a more in-depth tour of Tai' an. Zaozhuang tourism in the wisdom of the trial stage focused on tourism marketing campaign, which launched the tour "One Card" system, including two tickets and hotels, and attractions in the use of the world's eye [9].

\section{Framework Design of Shandong Province Wisdom Tourism}

Core technologies of wisdom of tourism information systems are engineering cloud computing, networking, communications, and mobile terminal. Lingyun Zhang considers that the wisdom of tourism theoretical system capacity should be built from three levels such as ability of travel wisdom attributes of wisdom tourism, and applications of wisdom tourism [1]. Ability of wisdom tourism focuses on emphasizing tourism information system platform to integrate the various information technology capabilities, otherwise, wisdom tourism-oriented applications are 
differentiated into different objects applications, such as applications for tourists, business-oriented applications for government applications and application-oriented and other residents.

Level-system Design of Wisdom Tourism in Shandong Province. This paper draws the existing researches on wisdom tourism and uses information systems planning and design method to design Shandong Province Tourism wisdom conceptual and functional framework. This research, on the one hand, emphasizes the application platform to consider the wisdom of tourism in different subjects, and on the other hand, tries to build a prototype system based on the provincial, municipal, and scenic intelligence platform concept, function, design, and implementation techniques.

Data Acquisition Module. Data acquisition module is such level that receives information from various tourism enterprises, which transfers various information to tourists through the wisdom tourism system. Data acquisition module is directly facing the tourist level, which focuses on strengthening the construction of the receiving device in the wisdom tourism, such as the various types of tourism resources in the main hotels, tourist attractions, public transport and urban public facilities, and other data. Specifically, data acquisition module uses RFID, infrared sensors, and laser scanning technology IOT into the net to collect tourist attractions, tourism enterprises and related information, such as operational status in reality.

Data Processing Module. Data processing module means the data processing capability of wisdom tourism, which is also an important distinction between the general and the wisdom of tourism. At present, many of China's cities are able to complete the reality of travel information collection and aggregation by building information service terminal, which means local governments can timely understand the real-time situation of tourist attractions, as well as the operation of tourist traffic between tourism enterprises and other operations. But there are still lack of large data analysis and data sharing, so that in the actual travel, many tourists generally perceive themselves simply as a passive recipient of information, but cannot achieve information interaction between enterprises and tourism. As mentioned above, the data processing module should focus on feedback and communication of tourist information. Wisdom tourism, on the one hand, should pay attention to establish a database of tourism infrastructure, on the other hand, ensure that the information resources can be effectively used interchangeably in the cloud platform, which is a prerequisite for the protection of tourism resources to the greatest extent, management and scheduling. For tourists, the emergence of powerful data processing module tourism, tourism can help facilitate the process of obtaining information on travel services, and based on the full exchange of information, visitors can tour the higher quality of the tourism experience.

Application Modules. Application module is reality specific operation level in wisdom tourism, which is the $\mathrm{f}$ the key step result of the data acquisition module and the data processing module in reality. Li suggested that the wisdom tourism should involve four subjects, namely tourists, tourist attractions, tourism administrations and businesses and other tourist destinations [3]. So in terms of design wisdom tourism operation layer, we need to balance the interests of the four, establish a comprehensive system for the wisdom tourism to run different tourist service groups, and improve service processes, achieve integrated service capabilities to enhance the quality of tourism services. The application modules for tourists should be able to process the information of tourism enterprises and scenic area to tourist. The application modules for tourist attractions can respond the information within the area, such as the flow of tourists, traffic statistics, and the unexpected situations within the scenic area, in order to optimize for the allocation of resources within the area of tourism. The role of the application function module for businesses in destination, such as hotels, restaurants, shopping and other tourism enterprises, is to guide tourism enterprises to sales and marketing, provide consumers with a variety of useful products of value-added experience, and effectively improve the level of information of tourism enterprises on the basis of information related to product innovation. For government administration, application modules can help it to monitor tourism enterprises operating conditions, and finish in-depth data mining through the cloud platform data processing module to achieve technical, efficiency, digitization of government surveillance. By this way, government administration is able to direct and guide tourist attractions and tourist destinations businesses to provide quality services to improve their efficiency and level 
of service.

Framework Design of Shandong Province Wisdom Tourism. The main contents of Shandong wisdom Tourism is to study how to use Shandong provincial intelligence platform layout, municipal intelligence platform integration, and enterprise intelligence platform access methods to structure Shandong Province wisdom tourism platform. Wisdom tourism development is a systematic project involving system planning, system design, operations planning and other aspects. Terminal Services object of wisdom tourism are tourists, so visitors' demand are core of planning and design.

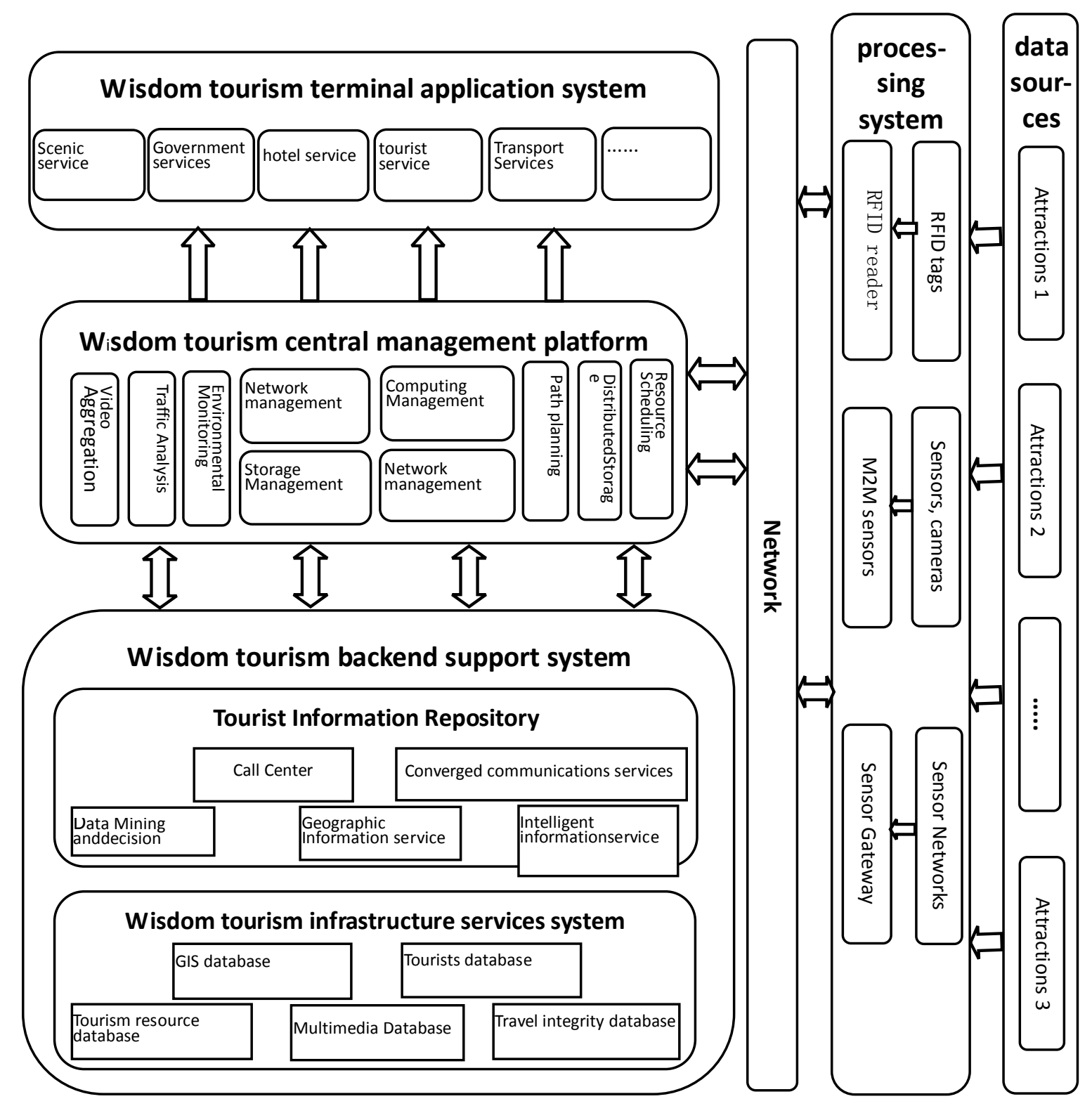

Figure 1. Travel system architecture wisdom

Shandong Province has broader distribution of tourism resources, so visitors will likely need for different services in province-wide area. Therefore, we proceed from the overall planning and embodied the wisdom tourism in the three levels of independent platform, which are provincial intelligence platform, municipal intelligence platform, and enterprise intelligence platform. According to user needs, platform-specific features of the level are achieved by the various levels of the system. System design framework is shown in Fig 1. Data acquisition modules are responsible for data acquisition, mainly from the attractions. Data processing modules include all data and perception of urban public administration as well as part of the data integration platform, such as GPS, Digital City. 
Wisdom tourism user terminal system design goals: visitors entering the Shandong Province can receive prompt installation of mobile APP and enjoy eating, drinking, playing music series smart tourism services, shopping, housing, and so on. The vast majority of wisdom tourism user terminal system is location-based services (LBS), which means once the customer arrival cities, neighborhoods, and scenic spots, the system would have to provide customers with the services they need, and all the services are available for online transactions, Reservations evaluation [10].

The design wise tourism platform of Shandong Province should follow the principles from macro to micro, taking into account both the needs of the province's tourism strategy of development strategy and realities of local government and the tourism business.

Design of Wisdom Provincial Tourism Platform System. Wisdom provincial tourism platform is responsible for the wisdom of the platform standard and unified interface around the city. This platform avoids duplication, a useless information silos, information and promotes resources of the collaborative operation within the province. It is mainly responsible for the strategic direction and goals for the level of intelligence platform construction layout, supervision and coordination of provincial and municipal platform, APP development of the province layout work. By using provincial wisdom tourism platform, we can to achieve scientific deployment from the angle of Shandong province tourism resources, such as public transport scheduling, scenic capital investment and repair schedule. At the same time, provincial platform can integrate municipal and enterprise-class wisdom tourism platform, develop application functions with APP and intelligent terminals.

Design of Wisdom Municipal Tourism Platform System. Municipal intelligence platform is responsible for establishing certain data sharing and service mechanism in tourist areas within the jurisdiction of their own, constructing the urban and regional spatial information infrastructure, and sharing business data with provincial intelligence platform. Municipal intelligence platform is particularly crucial to realize the wisdom of catering services, transportation, and navigation, shopping, and city public scenic. Meanwhile, municipal intelligence platform enables visitors to select personalized travel plan, tailors exclusively for visitors to their travel programs, and helps visitors away from the public line to ease congestion

Design of Tourism Enterprises Wisdom Tourism Platform. Enterprise-class intelligence platform is responsible for docking among the various attractions, hotels, public transport, travel, entertainment agencies and tourists to achieve the wisdom of Shandong Province tourism platform end function. In addition, scenic preview, scenic online $Q$, and attractions Smart tag (learn attractions allusions, history, etc.) can be realized by this platform. The tourists can obtain food, transportation, travel and play integration service, share travel experience, recommend personalized attractions, and find travel friends to improve themselves' efficiency and satisfaction.

\section{Conclusion}

This paper argues that the wisdom tourism involves four main aspects, but from the perspective of the supply market demand, the needs of tourists and the wisdom of experience are the keys to the success of the tour, so the wisdom of starting and ending points of tourism are tourists. Wisdom tourism platform in this paper emphasizes the vertical longitudinal design among the provincial, municipal and tourist attractions, and emphasizes tourism information from the data acquisition module, data processing module and application function module in the information downstream angle. Meanwhile, this paper subdivided wisdom tourism support system into support system, central management platform and application platform from the perspective of tourists. Therefore, in future wisdom tourism development design, market demand should emphasize the tourists' requirements. With the development of tourism and tourist market matures, more and more tourists tend to self-tour, who needs information to be much higher than traditional team tourists. From the tourist point of view, in order to help tourists obtain high-quality travel experience, the wisdom tourism should consider the needs of tourists as the fundamental starting point, increase the use of modern communication technologies in the tourism industry, and improve the quality of tourism enterprises service and optimize the management of tourism enterprises. Thus, in the build process, 
Shandong Province wisdom tourism platform system should grasp the current tourists in pursuit of individual experience and perception of tourism effectively from the perspective of individual tourists and realize the wisdom of the great development of tourism in the province.

In the wisdom tourism development process, there are some challenges and difficult issues for the current status of tourism development.

First, we should grasp the wisdom of tourism development stage strategy, focusing on different point at different times. In the initial stage, we should improve the tourism facilities based on the information for the subject, after that, construct tourism intelligence information repository, and support appropriate tourism central management platform to achieve intelligent management. In the implementation process we can select more mature scenic tourism pilot projects to carry out wisdom tourism, try to build miniature tourist information system, and derive benefit large-scale promotion of the wisdom of travel experience.

Secondly, in the wisdom of tourism development, three platform designs should take the principles of information systems, and emphasize the promotion role of Shandong provincial government and participation role of tourism enterprises, tourism public service system, and tourists. In the wisdom tourism development, the government should uphold the regulation and direction as the leading role, give initiative to municipal and tourism business intelligence platform, and form the urban wisdom tourism flourishing state and introduce innovative wisdom tourism products in accordance with current situation features.

Third, we should pay attention to the integration of a variety of tourism resources, which means the integration of tourism resources, tourism information resource and tourist information platform. This paper proposes to integrate tourist information resources in the province, optimize the distribution of information within their system resource distribution, and achieve Tourist information resources integration in the province. The wisdom tourism should firstly re-integrate tourism resources in the province and enhance the quality of the travel experience of tourists in Shandong Tourism through seamless travel information. After that, we can mine potential tourists spending power by innovating features comprehensive travel products and share the real travel information among province tourist attractions, tourism enterprises and tourists. In addition, using the existing mature information platform, such as navigation, Baidu perimeter, third-party payment platform, the public comment, airlines, and business travel platform to integrate tourist information in connection with the Shandong Province wisdom tourism platform, and obtain ultimately win-win cooperation in line with the hospitality Shandong idea.

\section{Acknowledgements}

This project was supported by Social Science Planning Project Foundation of Shandong Province (No.14CGLJ01), and partly supported by National Natural Science Foundation of China under Grant 71301089, 71471103, 71272122, and 71501113.

\section{References}

[1] L.Y. Zhang, N. Liu and M Liu: Tourism Tribune, Vol.5 (2012) No.27, p.66.

[2] J.L. Liu and Y.F. Fan: Chong Qing Social Science, Vol.10 (2011), p.121.

[3] M. Li: Chinese Public Adminstration, Vol. 6 (2012), p. 64.

[4] M. Yan: China Economic and Trade Herald, Vol.7 (2012), p.75.

[5] D.N. Song, X.L. Du and H.Y. Wang: Theory Research, Vol. 13 (2012), p.75.

[6] P. Shen and W.Y. Shu: Zhejiang's Economy, (2012) No.1, p.48.

[7] G.Z. Yao and L.H. Han: China Business and Trade, (2014) No.12, p. 127.

[8] Information on http:// www.shandong.gov.cn 
[9] H. Ji: Internet of Things Technologies, (2012) No.12, p.73.

[10] Y.Q. Yang, Y. Liu, H.X. Li and B.H. Yu: Industrial Management \& Data Systems, Vol.115 (2015) No.2, p. 253. 